\title{
Vaginal versus intramuscular progesterone for prevention of preterm labour in women with a twin pregnancy: A randomized controlled trial
}

\section{Original Article}

\author{
Waleed Hitler Tantawy, Mahmoud Mohammed Ghaleb,
}

Mahmoud Mohammed Abdulwehab Elsayed
Obstetrics and Gynecology Department, Faculty of Medicine, Ain Shams Universityt

\begin{abstract}
Background: Twins constitute $2-4 \%$ of all births and the rate of twining has increased by $76 \%$ between 1980 and 2009 . Twin pregnancies, compared with singletons, are at increased risk for fetal anomalies, preterm births, aberrant fetal growth, cerebral palsy and perinatal and infant mortality. Maternal complications associated with twin pregnancies include hypertensive disorders, gestational diabetes, cesarean delivery, postpartum hemorrhage and maternal mortality.

Aim of the Work: This study aimed to assess the efficacy of vaginal progesterone compared to intramuscular therapy in decreasing the rate of preterm birth in women with twin pregnancies.

Patients and Methods: This randomized controlled trial included women presented to Ain- Shams University Maternity Hospital. The study presented for approval from the Ethical Committee of the Department of Obstetrics and Gynecology, Faculty of Medicine, Ain-Shams University. Informed consent was signed after explaining the study purpose and methods to the subjects. Data presentation did not include the patient name, but diagnosis was included.

Results: There was no statistically significance between the two groups regarding number of neonatal RDS, NICU admission and neonatal death. Birth weight was significantly higher among vaginal group. NICU stay was significantly higher among intramuscular group.

Conclusion: Compared with intramuscular 17-OHPC, vaginal progesterone in women with twin pregnancy is associated with lower percentage of preterm labour, less recurrent spontaneous preterm birth, less adverse maternal side effects, fewer NICU admissions and better compliance.
\end{abstract}

Key Words: Intramuscular Progesterone, Preterm Labour, Twin Pregnancy, Vaginal.

Received: 15 August 2018, Accepted: 28 August 2018

Corresponding Author: Mahmoud Mohammed Abdulwehab Elsayed, Obstetrics and Gynecology Department, Faculty of Medicine, Ain Shams Universityt, E-mail: mahmoud.abdulwehab@gmail.com

ISSN: 2090-7265, November 2018, Vol.8, No. 4

\section{INTRODUCTION}

Twins constitute $2-4 \%$ of all births and the rate of twining has increased by $76 \%$ between 1980 and 2009 . Twin pregnancies, compared with singletons, are at increased risk for fetal anomalies, preterm births, aberrant fetal growth, cerebral palsy and perinatal and infant mortality. Maternal complications associated with twin pregnancies included hypertensive disorders, gestational diabetes, cesarean delivery, postpartum hemorrhage and maternal mortality (Ananth et al., 2012).

The causes for preterm birth in twins are classified into three clinical subtypes; preterm birth after (preterm) premature rupture of membranes (PROM), spontaneous onset of labour, (these two groups are termed spontaneous preterm birth) and medically indicated preterm birth after iatrogenic obstetrical interventions for maternal-fetal indications (Alexander et al., 2006).
Progesterone is a key hormone for pregnancy maintenance and a decline in progesterone action is considered to be central to the initiation of parturition in most of the mammalian species including primate (Lei et al., 2011).

This hormone acts in all components of the common pathway of parturition and promotes myometrial quiescence, inhibits cervical ripening and down-regulates the production of chemokines [such as interleukin (IL)-8] by the chorioamniotic membranes (Romero et al., 2007).

Importantly, the administration of progesterone receptor antagonists [i.e. mifepristone (RU486) or onapristone (ZK98299)] to pregnant women, nonhuman primates and guinea pigs can induce the onset of labour and cervical ripening (Romero et al., 2007). 
Thus, it is not surprising that many investigators have explored the use of progesterone for the prevention of preterm birth. Two compounds with progestational action have been used in clinical trials; progesterone, the bioequivalent of the natural hormone, and 17-alphahydroxyprogesterone caproate (17OHP-C), a synthetic ester, in which the caproate is added to prolong the halflife of the compound (Romero et al., 2007). The two molecules have different physiologic properties and clinical effectiveness in the prevention of preterm birth.

The vaginal route of administration results in higher local concentrations in the uterus, but the blood levels of progesterone are low; while the intramuscular route of administration results in optimal blood levels. A previous study found that the use of vaginal progesterone was more effective than intramuscular progesterone for the prevention of preterm birth before 34 weeks of pregnancy (Maher et al., 2013).

However, no well-designed and randomized trials have assessed the efficacy of progesterone in prolonging pregnancy in selected women with twin pregnancy, and uncertainty continues to surround the indications for its use and route of administration. We conducted a randomized controlled trial to evaluate the use of vaginal versus intramuscular injection of progesterone to reduce the risk of preterm birth (PTB) in women with twin pregnancies.

\section{AIM OF THE WORK}

This study aimed to assess the efficacy of vaginal progesterone compared to intramuscular therapy in decreasing the rate of preterm birth in women with twin pregnancy.

\section{PATIENTS AND METHODS}

- Type of Study: Randomized Controlled Trial

- Study Population: Women presented to AinShams University Maternity Hospital with the following criteria:

Inclusion criteria: Age between 20 and 35 years, any parity, carrying twin pregnancy and at a gestational age before 20 weeks.

Exclusion criteria: Fetal anomaly, advanced cervical dilatation, membranes bulging into the vagina in asymptomatic women, women who planned to undergo cervical cerclage or who already had cerclage inserted at another hospital, singleton pregnancy and any contraindication for progesterone therapy (known active liver disease or active thromboembolism).

Sample Size: Sixty cases were randomized into two groups; each group included 30 cases.

\section{Sampling Method:}

Randomized sampling: The participants were randomized using a computer-generated random list. The statistician generated the random allocation sequence and the investigators enrolled the participants.

The participants were distributed into two equal groups; each of them contains 30 pregnant women. Length of the current pregnancy was determined clinically using the last menstrual period with ultrasonographic confirmation. For all patients, progesterone treatment began before 20 weeks of gestation following randomization and continued until 36 completed weeks of gestation or the occurrence of premature rupture of membranes or preterm birth (PTB). In addition to progesterone treatment, all patients were educated about the symptoms of PTB.

All women were notified about the possible maternal side-effects from progesterone therapy that include headache, breast tenderness, nausea, cough and local irritation if administered intramuscularly. Also, reassurance and changing of injection site was performed. Participants assigned to the intramuscular progesterone group received, supervised weekly, intramuscular injections of 250 $\mathrm{mg}$ hydroxyprogesterone caproate in a total volume of $1 \mathrm{~mL}$ in the clinic ( $\square$ Cidolut Depot Ampule ; each $1 \mathrm{ml}$ ampoule contains $250 \mathrm{mg} 17$ alpha hydroxyprogesterone caproate in an oily solution produced by Chemical Industries Development "CID"). Whereas, those in the vaginal progesterone group received vaginal micronized progesterone suppositories (®Prontogest Supp ; each contains 400 $\mathrm{mg}$ of bio-identical progesterone produced by Marcyrl Pharmaceutical Industries) ; the participants used it daily at home. Enough progesterone was provided to all women in the vaginal progesterone group to last between clinic visits. Also, they were informed about how to obtain additional medication in case of missed clinic appointments. Treatments were continued until 36 weeks or the date of preterm birth.

Statistical Analysis: IBM SPSS statistics (Statistical Package for Social Sciences) software version 22.0, IBM Corp., Chicago, USA, 2013. Descriptive statistics will be done for quantitative data as minimum and maximum of the range as well as mean $\pm \mathrm{SD}$ (standard deviation), while it will be done for qualitative data as number and percentage. Inferential analyses will be done for quantitative variables using independent t-test in cases of two independent groups. In qualitative data, inferential analyses for independent variables will be done using Chi square test for differences between proportions and Fisher's exact test for variables with small expected numbers. 


\section{RESULTS}

Table 1: Demographic characteristics among the studied groups

\begin{tabular}{|c|c|c|c|c|}
\hline Items & Measures & $\begin{array}{l}\text { Vaginal } \\
(\mathrm{N}=28)\end{array}$ & $\begin{array}{c}\text { Intramuscular } \\
(\mathrm{N}=27)\end{array}$ & $\mathrm{P}$ \\
\hline Age & Mean \pm SD & $28.3 \pm 2.4$ & $28.9 \pm 2.0$ & $\wedge$ \\
\hline (years) & Range & $23.0-35.0$ & $24.0-34.0$ & 0.347 \\
\hline BMI & Mean \pm SD & $25.3 \pm 1.5$ & $25.6 \pm 1.5$ & $\wedge$ \\
\hline$\left(\mathrm{kg} / \mathrm{m}^{2}\right)$ & Range & $22.9-28.7$ & $23.0-28.4$ & 0.454 \\
\hline \multirow{2}{*}{ Parity } & Primiparous & $9(32.1 \%)$ & $10(37.0 \%)$ & \# \\
\hline & Multiparous & $19(67.9 \%)$ & $17(63.0 \%)$ & 0.703 \\
\hline \multirow{2}{*}{ GA at enrollment (week) } & Mean \pm SD & $16.7 \pm 0.9$ & $16.9 \pm 1.1$ & $\wedge$ \\
\hline & Range & $15.0-19.0$ & $15.0-19.0$ & 0.774 \\
\hline
\end{tabular}

^Independent t-test, \#Chi square test

No significant difference between the studied groups regarding demographic characteristics was found.

Table 2: Progesterone side effects among the studied groups

\begin{tabular}{|c|c|c|c|c|}
\hline Side effects & $\begin{array}{l}\text { Vaginal } \\
(\mathrm{N}=28)\end{array}$ & $\begin{array}{c}\text { Intramuscular } \\
(\mathrm{N}=27)\end{array}$ & andP & $\begin{array}{c}\mathrm{RR} \\
(95 \% \mathrm{CI})\end{array}$ \\
\hline Headache & $3(10.7 \%)$ & $5(18.5 \%)$ & 0.469 & $0.71(0.28-1.79)$ \\
\hline Cough & $1(3.6 \%)$ & $2(7.4 \%)$ & 0.611 & $0.64(0.13-3.25)$ \\
\hline Nausea & $1(3.6 \%)$ & $3(11.1 \%)$ & 0.352 & $0.47(0.08-2.63)$ \\
\hline Flushing & $1(3.6 \%)$ & $3(11.1 \%)$ & 0.352 & $0.47(0.08-2.63)$ \\
\hline Breast tenderness & $1(3.6 \%)$ & $2(7.4 \%)$ & 0.351 & $0.47(0.08-2.63)$ \\
\hline Vaginal discharge & $4(14.3 \%)$ & $1(3.7 \%)$ & 0.353 & $1.67(0.99-2.82)$ \\
\hline Vaginal brurities & $2(7.1 \%)$ & $1(3.7 \%)$ & 1.000 & $1.33(0.57-3.10)$ \\
\hline Injection bruises & $0(0.0 \%)$ & $5(18.5 \%)$ & $0.023^{*}$ & -- \\
\hline Injection brurities & $0(0.0 \%)$ & $2(7.4 \%)$ & 0.236 & -- \\
\hline
\end{tabular}

\#Chi square test, andFisher's Exact test

General progesterone side effects were non-significantly more frequent among intramuscular group. Also, injection site bruises was significantly more frequent among intramuscular group. Moreover, vaginal side effects were non-significantly more frequent among vaginal group.

Table 4: Delivery characteristics among the studied groups

\begin{tabular}{|c|c|c|c|c|c|}
\hline \multicolumn{2}{|c|}{ Items } & $\begin{array}{l}\text { Vaginal } \\
(\mathrm{N}=28)\end{array}$ & $\begin{array}{l}\text { Intramuscular } \\
(\mathrm{N}=27)\end{array}$ & $P$ & $\begin{array}{c}\mathrm{RR} \\
(95 \% \mathrm{CI}) \\
\end{array}$ \\
\hline \multicolumn{2}{|c|}{ Hospitalization (n, \%) } & $4(14.3 \%)$ & $6(22.2 \%)$ & and 0.446 & $0.75(0.34-2.63)$ \\
\hline \multicolumn{2}{|c|}{ PROM (n, \%) } & $2(7.1 \%)$ & $3(11.1 \%)$ & and0.669 & $0.77(0.25-1.68)$ \\
\hline \multicolumn{2}{|c|}{ CS delivery } & $24(85.7 \%)$ & $21(77.8 \%)$ & and 0.503 & $1.33(0.60-2.99)$ \\
\hline \multirow{3}{*}{$\begin{array}{l}\text { GA at delivery } \\
\text { (weeks) }\end{array}$} & Mean \pm SD & $36.6 \pm 1.9$ & $35.1 \pm 3.0$ & \multirow{2}{*}{${ }^{\wedge} 0.029 *$} & \multirow{2}{*}{--} \\
\hline & Range & $30.0-38.0$ & $29.0-38.0$ & & \\
\hline & $<32$ week & $2(7.1 \%)$ & $3(11.1 \%)$ & \multirow{3}{*}{ and 0.603} & \multirow{3}{*}{--} \\
\hline \multirow{2}{*}{$\begin{array}{l}\text { GA at delivery ranges } \\
(\mathrm{n}, \%)\end{array}$} & 32-36 week & $4(14.3 \%)$ & $6(22.2 \%)$ & & \\
\hline & $\geq 37$ week & $22(78.6 \%)$ & $18(66.7 \%)$ & & \\
\hline \multicolumn{2}{|c|}{ Preterm delivery (n, \%) } & $6(21.4 \%)$ & $9(33.3 \%)$ & $\# 0.332$ & $0.73(0.37-1.44)$ \\
\hline
\end{tabular}

${ }^{\wedge}$ Independent t-test, \#Chi square test, andFisher's Exact test, *Significant 
The study also revealed that hospitalization, PROM and preterm delivery were non-significantly more frequent among intramuscular group. CS delivery was non- significantly more frequent among vaginal group. GA at delivery was significantly higher among vaginal group. Delivery rate was significantly higher among vaginal group.

Table 5: Neonatal side effects among the studied group

\begin{tabular}{|c|c|c|c|c|c|}
\hline \multicolumn{2}{|c|}{ Side effects } & $\begin{array}{l}\text { Vaginal } \\
(\mathrm{N}=56)\end{array}$ & $\begin{array}{c}\text { Intramuscular } \\
\quad(\mathrm{N}=54)\end{array}$ & $\mathrm{P}$ & $\begin{array}{c}\mathrm{RR} \\
(95 \% \mathrm{CI})\end{array}$ \\
\hline \multirow{2}{*}{$\begin{array}{l}\text { Birth weight } \\
\quad(\mathrm{kg})\end{array}$} & Mean \pm SD & $2.4 \pm 0.3$ & $2.2 \pm 0.3$ & \multirow{2}{*}{${ }^{\wedge} 0.017^{*}$} & \multirow{2}{*}{--} \\
\hline & Range & $1.8-2.9$ & $1.4-3.0$ & & \\
\hline \multicolumn{2}{|c|}{$\operatorname{RDS}(\mathrm{n}, \%)$} & $5(8.9 \%)$ & $11(20.4 \%)$ & $\# 0.089$ & $0.58(0.27-1.22)$ \\
\hline \multicolumn{2}{|c|}{ Severe sepsis } & $1(1.8 \%)$ & $3(5.6 \%)$ & $\begin{array}{c}\text { and } \\
0.359\end{array}$ & $0.48(0.09-2.66)$ \\
\hline \multicolumn{2}{|c|}{ NICU (n, \%) } & $13(23.2 \%)$ & $18(33.3 \%)$ & $\# 0.238$ & $0.77(0.49-1.22)$ \\
\hline \multirow{2}{*}{$\begin{array}{l}\S N I C U \text { saty } \\
\text { (days) }\end{array}$} & Mean \pm SD & $8.6 \pm 1.9$ & $10.7 \pm 1.5$ & $\wedge$ & \multirow[b]{2}{*}{--} \\
\hline & Range & $6.0-12.0$ & $8.0-13.0$ & $0.002 *$ & \\
\hline \multicolumn{2}{|c|}{$\begin{array}{l}\text { Neonatal death } \\
\quad(\mathrm{n}, \%)\end{array}$} & $1(1.8 \%)$ & $3(5.6 \%)$ & $\begin{array}{c}\text { and } \\
0.359\end{array}$ & $0.48(0.09-2.66)$ \\
\hline
\end{tabular}

$\S$ Among NICU admitted cases, ^Independent t-test, \#Chi square test, andFisher's Exact test, *Significant

Also, the study indicated that RDS, NICU admission and neonatal death were non-significantly more frequent among intramuscular group. Birth weight was significantly higher among vaginal group. NICU stay was significantly higher among intramuscular group.

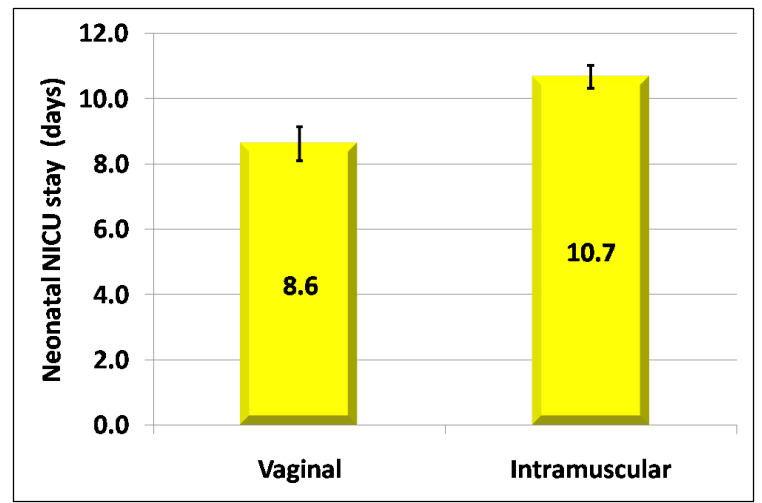

Fig. 1: Neonatal NICU stay among the studied groups

\section{DISCUSSION}

The present study is a prospective randomized controlled one that was conducted at Ain-Shams University Maternity Hospital in the period between October 2017 and August 2018. It aimed to evaluate the effect of vaginal progesterone suppository versus intramuscular injection of 17-hydroxyprogesterone caproate for prevention of spontaneous preterm labour and avoiding the perinatal morbidities and mortality in twin pregnancies among 60 women divided into two equal groups.

In this study, 76 women were eligible for the study. Among them, 60 consented to participate and were divided into two groups with 30 women in each. They were randomized to the mode of administration of progesterone. The first group consisted of 28 patients with two women lost in follow up. Concerning the demographic data of the first group, the mean age was 28.3 years, the mean BMI was 25.3, the mean gestational age at enrollment was 16.7 weeks and regarding the parity 9 of the women was PG and 19 were multipara. The second group consisted of 27 patients with three women lost in follow up. Concerning the demographic data of the second group, the mean age was 28.9 years, the mean BMI was 25.6, the mean gestational age was 16.9 weeks and regarding the parity 10 of the women were PG, and 17 were multipara table $(1,2,4,5)$.

The current study showed that there is no statistically significance between the two groups regarding number of neonatal RDS, NICU admission and neonatal death ; but lower percentage among vaginal progesterone group. Birth weight was significantly higher among vaginal group. NICU stay was significantly higher among intramuscular group fig. (1).

Concerning the date of delivery of 55 cases, there were 15 preterm deliveries (before completing 37 weeks of gestations). The incidence of preterm delivery in the vaginal progesterone group was $6(21.4 \%)$ and in the intramuscular group was $9(33.3 \%)$ and the difference was statistically non-significant with lower percentage of preterm deliveries among the vaginal progesterone group.

General progesterone side effects were nonsignificantly more frequent among intramuscular group. Injection site bruises was significantly more frequent among intramuscular group. Vaginal side effects were nonsignificantly more frequent among vaginal group. 
Our results are in consistent with Maher et al., 2013 in which a total of 547 women carrying a singleton pregnancy at a gestational age between 14 and 18 weeks were eligible for the study. Among them, 518 consented to participate. They were randomized to the mode of administration of progesterone; 262 were randomized to vaginal progesterone, while 256 were allocated to intramuscular progesterone. All deliveries before 34 weeks of gestation (primary outcome) were compared between the groups. Vaginal progesterone was associated with a lower percentage of deliveries than the intramuscular preparation $(\mathrm{p}=0.02)$. This association was also observed between 28 and 32 weeks of gestation $(p=0.04)$. No statistically significant difference was observed between the groups regarding deliveries at other weeks of gestation.

These reductions in PTB were reflected in the number of neonatal Intensive Care Unit admissions $(15.4 \%$ in the vaginal group vs. $25.7 \%$ in the intramuscular group; $\mathrm{p}=$ 0.006). Our results are also in consistent with Saccone et al. (2017) that published a systematic review with meta-analysis to evaluate the efficacy of vaginal progesterone compared with 17-OHPC in prevention of spontaneous preterm birth (SPTB) in singleton gestations with prior SPTB.

Three randomized controlled trials (RCTs) (680 women) were included. The mean gestational age at randomization was about 16 weeks. Women were given progesterone until 36 weeks or delivery. Regarding vaginal progesterone, one study used $90 \mathrm{mg}$ gel daily; while the other one used $100 \mathrm{mg}$ suppository daily. Also, the other one used 200 mg suppository daily. All the included trials used 250 mg 17-OHPC weekly as comparison group. Women who received vaginal progesterone had a significantly lower rate of SPTB $<34$ weeks (17.5\% vs $25.0 \%$; RR $0.71,95 \%$ CI 0.53 to 0.95 ; low quality of evidence) and SPTB $<32$ weeks ( $8.9 \%$ vs $14.5 \%$; RR $0.62,95 \%$ CI 0.40 to 0.94 ; low quality of evidence) compared to women who received 17OHPC. There were no significant differences in the rate of SPTB $<37$ weeks, SPTB $<28$ weeks and SPTB $<24$ weeks. The rate of women who reported adverse drug reactions was significantly lower in the vaginal compared to 17 OHPC group (7.1\% vs $13.2 \%$; RR $0.53,95 \%$ CI 0.31 to 0.91 ; very low quality of evidence).

Regarding neonatal outcomes, vaginal progesterone was associated with a lower rate of neonatal intensive care unit admission compared to $17-\mathrm{OHPC}$ (18.7\% vs $23.5 \%$; RR $0.63,95 \%$ CI 0.47 to 0.83 ; low quality of evidence). This agreed with another published systematic review with meta-analysis (Oler et al., 2017) to evaluate the efficacy of vaginal progesterone compared with 17-OHPC in prevention of spontaneous preterm birth (SPTB) in singleton gestations with prior SPTB.
There were three randomized clinical trials that included vaginal progesterone and intramuscular $17 \alpha$ $\mathrm{OHP}$ as interventions for the prevention of recurrent preterm delivery of singleton pregnancies irrespective of cervical length including a total of 680 patients with a history of preterm delivery. Of these, $332(48.8 \%)$ patients were randomized to treatment with $17 \alpha-\mathrm{OHP}$ and 348 $(51.2 \%)$ to treatment with vaginal progesterone. The mean duration of pregnancy at randomization was 16 weeks. Treatment continued until 36 weeks of pregnancy or delivery. Delivery before 34 weeks of pregnancy was less frequent among patients treated with vaginal progesterone compared with those treated with $17 \alpha-\mathrm{OHP}(19.3 \%$ vs $26.7 \%$; RR $0.71,95 \%$ confidence interval [CI] 0.53-0.95).

Similarly, delivery before 32 weeks of pregnancy was also lower among patients treated with vaginal progesterone $(12.4 \%$ vs $16.1 \%$; RR 0.62 , 95\% CI 0.40 0.94). No difference was observed between the two treatment groups for delivery before 37 weeks or 28 weeks of pregnancy; however, non-significant trends favoring vaginal progesterone were observed for both outcomes. There were no differences between the rate of respiratory distress syndrome in the two groups (RR $1.02,95 \% \mathrm{CI}$ $0.65-1.60)$ or neonatal admission to the intensive care unit (RR 1.17, 95\% CI 0.49-2.79).

A lower rate of adverse treatment reactions was observed among patients treated with $17 \alpha$-OHP $(12.3 \%$ vs $17.4 \%$; RR 0.53 , 95\% CI $0.31-0.91$ ); however, this finding was based on data from a single study. Owing to insufficient data, another meta-analysis (Schuit et al., 2015) showed that vaginal progesterone may be effective in improving the perinatal outcome in women with twin pregnancies and sonographic short cervix $(\leq 25 \mathrm{~mm})$ when cervical length was measured at randomization or before 24 weeks of gestation. That was a very huge study that included 13 randomized controlled trials and used both types of progesterone natural vaginal and intramuscular 17-hydroxyprogesterone caproate. But, this result was only on a subgroup of women with a cervical length of $\leq 25 \mathrm{~mm}$. Also, the study was conducted on both mono and dichorionic twin

Another randomized clinical trial (Bafghi et al., 2015) in which seventy-eight pregnant women with singleton pregnancy and one risk factor of preterm delivery were included in the study. The subjects were assigned randomly to two groups; group one receiving vaginal progesterone and group two receiving 17- $\alpha$ hydroxyprogesterone caproate. Among the 39 births in group one, $33.3 \%$ occurred preterm and among the 39 births in group two, 30.7\% occurred preterm ( $<37$ weeks). The mean gestational ages at delivery in groups 1 and 2 were $37.07 \pm 2.23$ and $36.81 \pm$ 
2.77 weeks, respectively, $(p=0.765)$. The study concluded that vaginal progesterone and intramuscular progesterone can be equally useful in the prevention of preterm delivery.

Another randomized controlled trial (Shambhav et al., 2018) in which 100 women with a singleton pregnancy between 16 and 24 weeks of gestation and $\geq$ one prior spontaneous singleton PTB or midtrimester abortion were randomized to receive $200 \mathrm{mg}$ of vaginal progesterone effervescent tablet daily (Group A) or $250 \mathrm{mg}$ IM 17OHPC weekly (Group B) till 37 weeks of gestation or delivery. The spontaneous PTB rate $<37$ weeks was similar in the two groups $(20 \%$ in Group A and $20.8 \%$ in Group B, p 1/4.918). The PTB rate $<34$ weeks or $<28$ weeks were also comparable. The mean birth weight and other neonatal outcomes were similar. Twenty percent of women in Group A and $29.2 \%$ of women in Group B reported adverse effects from their respective study medications (p $1 / 4.408$, NS). Thus, no difference appeared between the vaginal progesterone effervescent tablet and 17-OHPC when used for the prevention of a recurrent PTB

A meta-analysis Romero et al. in women with a short cervical length showed that vaginal progesterone reduced PTB $<33$ weeks (RR $0.58,95 \%$ CI $0.42-0.80$ ) and the composite neonatal mortality and morbidity (RR 0.57, $95 \%$ CI $0.40-0.81)$. The trials included had used three formulations; suppositories (100 or $200 \mathrm{mg}$ ) and gel (90 $\mathrm{mg}$ ) and all were similarly efficacious (Romero et al. 2012).

Three placebo controlled trials using IM 17 OHPC or vaginal progesterone to prevent PTB found that progesterone was beneficial (Majhi et al. 2009). These trials had recruited only women with a prior PTB except for (Da Fonseca et al. 2003) who had recruited some women with other risk factors, though over $90 \%$ had a prior PTB.

Five randomized studies (similar to the present study) compared vaginal progesterone formulations with IM 17 OHPC or IM progesterone to prevent PTB in women at risk for a PTB (Elimian et al. 2016). Most of them found a similar efficacy of vaginal formulations (progesterone tablet or pessary) and IM formulations (progesterone or 17 OHPC) to prevent PTB in women at risk (Elimian et al. 2016).

However, Abd El Hameed (2012) found that the vaginal progesterone tablet and IM 17 OHPC were similarly effective in reducing PTBs in the subgroup of women with a prior PTB (16.6\% versus $14.3 \%)$, but the vaginal progesterone tablet was more effective in the subgroup with a short cervical length (9.1\% versus $28.9 \%)$.

Norman et al. (2016) also did not observe a reduction in the PTB rate $<34$ weeks with $200 \mathrm{mg}$ vaginal progesterone gelatine capsule ( $15 \%$ versus $17 \%$ with placebo) in women at risk for PTB (due to short cervical length or prior PTB or positive fibronectin with risk factors for PTB), though it had no benefit or harm in children seen until 2 years of age. As their primary outcome (childhood outcomes of progesterone to prevent PTB) was different from the planned outcomes of the other studies in the Cochrane review, a meta-analysis including their study was not possible.

The strengths of the study are that it was a randomized study and up to our knowledge no prior RCT has compared vaginal to intramuscular progesterone in women with twin pregnancy that is a considerable risk of PTB. All patients recruited to the study were with gestation age before 20 weeks making it a homogenous group. Modifiable risk factors for PTB (infections) were treated so that they did not interfere with the results and compliance to medication was ascertained. The vaginal progesterone effervescent tablet which was used has been reported to have an efficient mechanism for mucosal absorption (Paulson et al. 2014).

The lack of a control group may be considered as a limitation, but it was deemed unethical to withhold a medication which is the standard of care in such women. A small sample size proved to be limiting in drawing meaningful inferences, especially in spontaneous PTB rates at $<34$ and $<28$ weeks. Limitations of our study included that, previous trials included three different doses of daily vaginal progesterone were used $(90 \mathrm{mg}$ gel, and 100 and $200 \mathrm{mg}$ suppository) making it unclear which of these doses and/or formulations of vaginal progesterone should be preferred. Many outcomes were underpowered including neonatal outcomes.

\section{CONCLUSION}

Compared with intramuscular 17-OHPC, vaginal progesterone in women with twin pregnancy is associated with lower percentage of preterm labour, less recurrent SPTB, less adverse maternal side effects, fewer NICU admissions and better compliance.

\section{REFERENCES}

1. Abd El Hameed and Azza A. vaginal versus intramuscular progesterone in the prevention of preterm labor and their effect on uterine and fetal blood flow. Middle East fertility society 2012; 163 169.

2. Alexander GR, Kogan M, Martin J, et al. What are the fetal growth patterns of singletons, twins, and triplets in the United States? Clin Obstet Gynecol 1998; 41: 114 . 
3. Ananth CV, Kirby RS and Vintzileos AM. Recurrence of preterm birth in twin pregnancies in the presence of a prior singleton preterm birth. J Matern Fetal Neonatal Med 2008; 21: 289.

4. Bafghi AS, Bahrami E and Sekhavat L. Comparative Study of Vaginal versus Intramuscular Progesterone in the Prevention of Preterm Delivery: A Randomized Clinical Trial. Electron Physician 2015; 1301-9.

5. da Fonseca EB, Bittar RE., Carvalho MH, Zugaib M. Prophylactic administration of progesterone by vaginal suppository to reduce the incidence of spontaneous preterm birth in women at risk: a randomized placebocontrolled double-blind study. Am J Obstet Gynecol. 2003; 188: 419-424

6. Elimian A, Smith K, Williams M, Knudtson E, R. Goodman J and Marilyn B. A randomized controlled trial of intramuscular versus vaginal progesterone for the prevention of recurrent preterm birth. International Journal of Gynacology and Obstetrics 2016; 169-72.

7. Lei K, Chen L, Cryar BJ, et al. Uterine stretch and progesterone action.J Clin Endocrinol Metab. 2011 Jun; 96(6): E1013-24.

8. Maher MA, Abdelaziz A, Ellaithy M and Bazeed MF. Prevention of preterm birth: a randomized trial of vaginal compared with intramuscular progesterone. A C TA Obstetricia et Gynecologica 2013; 92:215-222.

9. Majhi P, Bagga R, Kalra J and Sharma M. Intravaginal use of natural micronized progesterone to prevent pre-term birth: a randomized trial in India. J obstet Gynaecol 2009; 493-8.

10. Norman JE, Marlow N, Messow CM, et al. Vaginal progesterone prophylaxis for preterm birth (the OPPTIMUM study): a multicentre, randomised, double-blind trial. Lancet 2016; 387: 2106.

11. Oler E, Ehe AC and Hesson A. Meta-analysis of randomized controlled trials comparing $17 \alpha$-hydroxyprogesterone caproate and vaginal progesterone for the prevention of recurrent spontaneous preterm delivery.Int J Gynaecol Obstet. 2017; 138(1):12-16.
12. Paulson RJ, Collins MG and Yankov VI. Progesterone Pharmacokinetics and pharmacodynamics with 3 dosages and 2 regimens of an effervescent micronized progesterone vaginal insert. J Clin Endocrinol Metab 2014; 4241-9.

13. Romero R, Nicolaides K, Conde-Agudelo A, et al. Vaginal progesterone in women with an asymptomatic sonographic short cervix in the midtrimester decreases preterm delivery and neonatal morbidity: a systematic review and metaanalysis of individual patient data. Am J Obstet Gynecol 2012; 206: 124.e1.

14. Romero R. Prevention of spontaneous preterm birth: the role of sonographic cervical length in identifying patients who may benefit from progesterone treatment. Ultrasound Obstet Gynecol. 2007 Oct; 30(5): 675-86.

15. Saccone G, Khalifeh, Elimian A, Bahrami E, Chaman-Ara K, Bahrami M and Berghella V. Vaginal progesterone compared to intramuscular 17-alphahydroxyprogesterone caproate for prevention of recurrent spontaneous preterm birth in singleton gestations: a systematic review and meta-analysis of randomized controlled trials. Ultrasound Obstet Gynecol. 2017; 49(3):315-321.

16. Schuit E, Stock S, Rode L, et al. Effectiveness of progestogens to improve perinatal outcome in twin pregnancies: an individual participant data metaanalysis. BJOG 2015; 122: 27.

17. Shambhavi S, Bagga R, Bansal P, Kalra J and Kumar P. A randomised trial to compare $200 \mathrm{mg}$ micronized progesterone effervescent vaginal tablet daily with $250 \mathrm{mg}$ intramuscular 17 alpha hydroxyl progesterone caproate weekly for prevention of recurrent preterm birth. Journal of Obstetrics and Gynaecology 2018; 800-806. 